\title{
ÉTICA AMBIENTAL, SUSTENTABILIDADE, PRINCÍPIO DA PREVENÇÃO E A RESSIGNIFICAÇÃO DO DIREITO DO TRABALHO
}

\section{ÉTICA AMBIENTAL, SOSTENIBILIDAD, PRINCIPIO DE LA PREVENCIÓN Y EL NUEVO CONTENIDO DEL DERECHO DEL TRABAJO}

\author{
${ }^{1}$ Flavia de Paiva Medeiros de Oliveira \\ ${ }^{2}$ Lucira Freire Monteiro
}

\section{RESUMO}

A finalidade do presente artigo é propor uma ressignificação do do Direito do Trabalho, sobretudo, do clássico instituto, conhecido como insalubridade. Para tanto, parte do pressuposto da ética ambiental como norte para imprimir à sustentabilidade um viés social e humano capaz de dirigir uma nova forma de pensar o Direito. A questão ambiental passa a ter uma perspectiva mais ampla, favorável a novos modos de pensar e agir, estendendo-se à formulação de uma nova concepção de ética relacionada à noção de sustentabilidade no ambiente trabalhista. Como tal o direito trabalhista reassume o caráter preventivo sobre atividades potencialmente causadoras de degradação do meio ambiente mediante um novo paradigma ético de sustentabilidade, fazendo com que cada vez mais ramos da ciência jurídica se inter-relacionem e cooperem entre si na ressignificação de institutos jurídicos clássicos que precisam ser relidos e atualizados à luz de um conteúdo ético. Nessa perspectiva, a ética ambiental e a sustentabilidade, restam pautadas sobre axiomas de reciprocidade e alteridade, cumprindo a finalidade de atuar como vetores de uma ressignificação do Direito do Trabalho.

Palavras-chave: Ética ambiental e sustentabilidade, Reciprocidade e alteridade, Prevenção e direito do trabalho

\footnotetext{
${ }^{1}$ Doutora em Direito do Trabalho pela Universitat de València - UV, València (Espanha). Professora de Direito pela Universidade Estadual da Paraíba - UEPB, Paraíba (Brasil). E-mail: flaviadepaiva@ hotmail.com

${ }^{2}$ Mestre em Sociologia Rural pela Universidade Federal da Paraíba - UFPB, Paraíba (Brasil). Professora e Coordenadora do Curso de Direito pelo Centro de Ciências Jurídicas da Universidade Estadual da Paraíba - UEPB, Paraíba (Brasil). E-mail: freirel@uol.com.br
} 


\section{RESUMEN}

La finalidad del presente trabajo es proponer una nueva significación para el derecho del trabajo, principalmente, para el clásico instituto conocido como insalubridad. Para ello, se parte del fundamento de la ética ambiental como hilo conductor para dar a la sostenibilidad una perspectiva social y humana, teniendo en cuenta la creación de una nueva forma de pensar el Derecho. A la cuestión ambiental se impone una connotación más amplia, que es favorable a los nuevos modos de pensar y actuar, que, además, es capaz de alcanzar una nueva idea de ética que tiene relación con la noción de sostenibilidad en el ambiente laboral. Así, el derecho del trabajo asume un carácter preventivo sobre actividades potencialmente generadoras de degradación del medio ambiente, por medio de un nuevo paradigma ético de sostenibilidad. Todo ello hace que las partes de ciencia jurídica se relacionen íntimamente y cooperen para la nueva interpretación de clásicos institutos que necesitan de una nueva interpretación y actualización de sus contenidos éticos. Por ello, la ética ambiental y la sostenibilidad se fundamentan en axiomas de reciprocidad y alteridad, con la finalidad de funcionaren como vectores de una nueva forma de pensar el derecho del trabajo.

Palabras-claves: Ética ambiental y sostenibilidad, Reciprocidad y alteridad, Prevención y derecho del trabajo 


\section{Introdução}

A necessidade de ressignificação de institutos clássicos do Direito do Trabalho se afigura presente no atual contexto jurídico como decorrência do tratamento constitucional atribuído ao meio ambiente e de uma nova dimensão dada à sustentabilidade, que a encara como vetor de desenvolvimento humano e social e não apenas econômico.

Esse novo conteúdo da sustentabilidade tem como ponto de partida a superação do paradigma de dominação do homem sobre a natureza, que passa a encará-lo como parte do meio ambiente, pelo que se impõe o respeito e o cuidado do ser humano para consigo mesmo e para com o próximo, instituindo um padrão de ética fundamentada na alteridade, isto é, uma ética ambiental.

A ética ambiental, ademais de possuir uma conotação social capaz de redirecionar a forma de pensar e agir da humanidade, também acarreta uma interdependência entre os ramos do Direito, que vai além da simples interpretação de normas jurídicas e desemboca em uma reformulação de institutos jurídicos, partindo de critérios ambientais, já que o meio ambiente se afigura como direito fundamental e humano que possui uma vertente individual e coletiva que merece ser tutelada.

Nesse sentido, a finalidade do presente artigo é propor uma ressignificação do clássico instituto do Direito do Trabalho, conhecido como insalubridade. Para tanto, parte-se de uma ideia de ética ambiental como norte para imprimir à sustentabilidade um viés social e humano capaz de dirigir uma nova forma de pensar o direito.

Esse novo modo de pensar a ciência jurídica, no presente caso, utiliza o princípio da prevenção para dar à insalubridade uma conotação mais social e humana do que monetária, a fim de propor bases para o alargamento dessa figura jurídica cuja maior consequência é a possibilidade de uma real interação do trabalhador com o meio ambiente no qual labora, sendo aquele responsável pelo cuidado e respeito para o com o seu entorno.

\section{1. Ética ambiental, sustentabilidade e meio ambiente do trabalho}

O tema "meio ambiente" não pode ser visto como um objeto específico, mas em interdependência e inter-relação com outros elementos e, em especial, com o homem e a 
sociedade na qual ele vive. Esta interdependência é observada de forma indiscutível pela relação homem-natureza, uma vez que ele não pode ser separado do seu entorno natural, pois este é condição imperativa para a sobrevivência humana.

Esta interdependência homem-natureza é ressaltada por Murgel Branco (1995, p.217), quando afirma:

O homem pertence à natureza tanto quanto - numa imagem que me parece apropriada - o embrião pertence ao ventre materno: originou-se dela e canaliza todos os seus recursos para as próprias funções e desenvolvimento, não lhe dando nada em troca. É seu dependente, mas não participa (pelo contrário, interfere) de sua estrutura e função normais. Será um simples embrião se conseguir sugar a natureza, permanentemente, de forma compatível, isto é, sem produzir desgastes significativos e irreversíveis; caso contrário, será um câncer, o qual se extinguirá com a extinção do hospedeiro.

A interação e interdependência do meio ambiente, portanto, pressupõe superar o paradigma de dominação que sempre caracterizou as relações entre o homem e o meio ambiente, levando a uma re(significação) que potencialize a ética da alteridade, com ênfase em valores fundamentais. Este novo modelo de organização planetária deve ter como alicerce a responsabilidade, o cuidado e o respeito do homem para consigo mesmo, para com o próximo, para com as outras espécies e, até mesmo, para com os demais componentes abióticos que constituem a biosfera.

Surge assim a necessidade de tratar a questão ambiental por uma perspectiva mais ampla que implante na sociedade uma nova forma de pensar e agir, tanto do ponto de vista individual, quanto coletivo, capazes de criar modelos de produção e relações sociais, no sentido amplo, aptos a suprirem as necessidades sociais, sem que, contudo, perpetuem desigualdades sociais, garantindo, ao mesmo tempo, uma sustentabilidade ecológica (WOLKMER; PAULITSCH, 2011, p. 225).

Essa nova forma de pensar e agir suplanta a visão tradicional de saber fundamentada em uma única área de conhecimento e impõe uma inter-relação entre as ciências e os saberes, de forma a que eles se entrelacem e criem uma sustentabilidade holística. Nesse sentido, Boff (2006, p. 5) assevera que:

A sustentabilidade deve possuir um caráter e uma abrangência holísticos, a sustentabilidade significa que no processo evolucionário e na dinâmica da natureza vigoram interdependências, redes de relações inclusivas, 
mutualidades e lógicas de cooperação que permitem que todos os seres convivam, co-evoluam e se ajudem mutuamente para manterem-se vivos e garantir a biodiversidade. A sustentabilidade vive do equilíbrio dinâmico, aberto a novas incorporações, e da capacidade de transformar o caos gerador de novas ordens (estruturas dissipativas de Ilya Prigogine)

Essa sustentabilidade que, obrigatoriamente, precisa ter um caráter holístico, leva à necessidade de inserção de uma nova ideia de ética, uma ética ambiental, que se arrima na existência de valores ecológicos, que partem de uma noção abrangente de natureza, como bem jurídico e social dotada de valor em si mesmo, e que não depende, para ser protegida, da necessidade e do interesse da espécie humana (WOLKMER; PAULITSCH, 2011, p. 225).

A formulação de uma nova concepção de ética influencia diretamente a noção de sustentabilidade, a ponto de imprimirem uma visão social inclusiva, que, partindo da lógica da cooperação, permita uma convivência harmônica do ser humano com o entorno no qual ele está incluído, sem que, todavia, ele seja encarado como senhor absoluto desse meio.

Esse novo paradigma ético e de sustentabilidade se refletem na nova forma de pensar o Direito, a ponto de levarem os ramos da ciência jurídica a se inter-relacionarem, e, mais do que isso, a cooperarem entre si na ressignificação de institutos jurídicos clássicos que precisam ser relidos à luz desse novo conteúdo ético. Nessa simbiose entre eles tem-se como incontornável uma inovação sobre a concepção de inclusão social, demandado pelo novo padrão de sustentabilidade.

A nova forma de pensar o Direito, partindo da ética ambiental e da sustentabilidade, torna imperiosa a releitura de institutos do Direito do Trabalho, tradicionalmente, interpretados à luz de critérios monetários e, eminentemente legais, onde se trocava a saúde e higidez do trabalhador por ganhos econômicos; por uma lógica preventiva e de precaução, na qual a pessoa trabalhadora passa a ser vista como parte integrante do meio ambiente natural e social do qual ela faz parte e não apenas do meio produtivo no qual ela labora. Somente assim é possível alcançar maiores patamares de inclusão social, vez que a saúde do ser humano que trabalha deixará, simplesmente, de ser trocada por dinheiro e passará a ser encarada como um critério da ética ambiental e da sustentabilidade que devem ser perseguidos, prioritariamente, pelo ordenamento jurídico, nem que para tanto seja necessário ressignificar instituições jurídicas. 
Nessa nova conjuntura de ética e de sustentabilidade, a saúde torna-se um valor a ser atingido como meta prioritária da justiça na esfera trabalhista, o que impõe a reformulação de institutos jurídicos. Nesse cenário, ganha destaque a necessidade de analisar o princípio da prevenção não apenas como vetor do Direito Ambiental, mas também como norteador do Direito do Trabalho, a fim de que tal axioma, ademais de ser discutido por uma perspectiva ambiental, seja tratado como garantia à saúde do trabalhador.

\subsection{Percurso histórico do princípio da prevenção em meio ambiente do trabalho}

A obrigação de prevenir o dano ambiental é, indubitavelmente, um princípio fundamental ou estrutural do Direito Ambiental, que deriva da necessidade de estabelecer critérios diligentes para uma utilização equitativa dos bens que compõem o meio ambiente.

Essa obrigação foi elevada à categoria de princípio na Declaração de Estocolmo de 1972, que, em seu Princípio 21, pretendia assegurar que os danos ambientais causados por atividades desenvolvidas dentro de um determinado Estado, não prejudicassem o meio ambiente de outros Estados ou as zonas situadas fora da jurisdição nacional. Posteriormente, em 1982, na Convenção das Nações Unidas sobre o Direito do Mar, esse princípio foi reafirmado no artigo 194.2 com igual contundência. Não com atraso, em 1992, na Declaração do Rio, o referido princípio foi novamente reiterado.

No âmbito do direito nacional, a obrigação de prevenir os danos ambientais aparece como consequência do disposto no artigo 225, caput, da CF/88. Faz-se necessário defender e prevenir os danos ao meio ambiente que, constitucionalmente, caracteriza-se como um bem de uso comum do povo ao qual todos têm direito e que, por ser essencial à sadia qualidade de vida, deve ser adequadamente tutelado, a fim de garantir que o seu uso pelas presentes e futuras gerações se dê de forma equitativa e equilibrada.

Todavia, ainda que a referência expressa à proteção do meio ambiente encontre seu fundamento mais imediato no citado artigo constitucional, não se pode olvidar que essa referência decorre da exigência de garantir a dignidade humana, reconhecida como princípio fundamental do atual Estado Democrático de Direito (CF/88, art. $\left.1^{\circ}\right)$. 
A concretização da dignidade humana como princípio fundamental do nosso Estado Democrático de Direito impõe uma detida análise da expressão "meio ambiente" sob uma perspectiva ampla, observado o seu objetivo de tutelar eficazmente a interação do conjunto de todos os elementos naturais, artificiais e culturais que propiciam o desenvolvimento equilibrado da vida em todas as suas formas (SILVA, 2000, p. 19-20). A tutela eficiente de todos os elementos que propiciam a vida em todas as suas formas permite que o ser humano tenha uma vida digna, ou seja, uma vida produtiva sadia.

Evidentemente, as atividades humanas cada vez mais agem sobre o meio ambiente, mas isso não justifica a atuação lesiva do homem sobre esse bem jurídico. Ao contrário, a essencialidade do meio ambiente e sua eficaz tutela exige que a atuação humana represente o menor risco possível ao bem ambiental. Em outros termos, o que se pretende com uma política ambiental preventiva é evitar o dano ambiental, ou seja, a degradação ambiental, considerada como a alteração adversa das características do meio ambiente (Lei 6.938/81, art. $3^{\circ}$, II).

Nesse contexto, o princípio da prevenção aparece como garantia jurídica através da qual se busca evitar as alterações adversas do meio ambiente, isto é, a degradação, por meio da adoção de um conjunto de medidas que, como regra geral, devem ser tomadas anteriormente à intervenção humana sobre o ambiente no qual se desenvolverá as atividades.

Há alteração adversa das características do meio ambiente e, portanto, dano ambiental, quando a intervenção humana sobre o seu entorno prejudica a saúde, a segurança e o bem-estar da população, e cria condições desfavoráveis à realização de atividades sociais e econômicas, afetando desfavoravelmente a biota ou as condições estéticas ou sanitárias do meio ambiente através do lançamento de matéria ou energia em desacordo com os padrões ambientais estabelecidos (Lei 6.938/81, art. $3^{\circ}$, III).

A finalidade do princípio da prevenção não é impedir a intervenção humana sobre o meio ambiente, senão assegurar que essa intervenção se desenvolva sem degradálo (alterar adversamente), o que exige que se atenda a pautas e critérios capazes de garantir a compatibilização do desenvolvimento econômico e social com a preservação da qualidade e do equilíbrio do entorno (Lei 6.938/81, art. $2^{\circ}$ c/c $4^{\circ}$, I e VI).

Nessa direção, o princípio da prevenção se destina a evitar a produção do dano, o que deve ser feito não apenas com a adoção de um modelo curativo, cujo objetivo resida 
eminentemente em indenizar as consequências lesivas derivadas da intervenção humana provocadora de degradação da qualidade ambiental, mas impondo a adoção de um modelo propriamente preventivo, que se antecipe às medidas irreversíveis que a degradação ambiental possa vir a sofrer e cuja reparação não seja feita somente através do pagamento de uma indenização à vítima do dano consumado.

Destarte, a atuação preventiva opera através de uma política de Estado por suas instituições, de modo que norteie a atuação tanto do Poder Público, como da coletividade em todos os âmbitos relacionados à vida em sociedade.

Esse caminho faz ver que a necessidade de prevenir os danos ambientais se estende também ao meio ambiente de trabalho, às condições que envolvem e condicionam, direta ou indiretamente, o local onde o homem obtém os recursos necessários para o seu sustento e o desenvolvimento da sociedade, já que a alteração adversa das características desse entorno laboral pode prejudicar a saúde, a segurança e o bem-estar do trabalhador, como também criar condições desfavoráveis à prestação da atividade laborativa, que se caracteriza como uma atividade econômica para o empregador e como uma atividade social para o trabalhador (Lei 6.938/81, art. $3^{\circ}$, III, "a" e "b").

A institucionalização da prevenção de danos ao meio ambiente do trabalho tem a finalidade de promover o bem-estar e a justiça social, e como ponto de partida o primado do trabalho (CF/88, art. 193), e encontra fundamento nos art. $7^{\circ}$, XXII, XXIII e XVIII e no art. 200, VIII, todos da Carta Magna brasileira em vigor. É a partir desses dispositivos constitucionais que se pode estabelecer a relação entre prevenção de riscos laborais e prevenção de danos ambientais, porquanto essas duas medidas preventivas tutelam o direito à vida e à saúde do ser humano.

Como consequência dessa relação existente entre prevenção de riscos laborais, defesa do meio ambiente e saúde, o Ministério do Trabalho elaborou a Norma Regulamentadora 9 (NR 9). Essa norma estabelece a obrigatoriedade de elaboração e aplicação, por parte de todo empreendimento que admita trabalhadores como empregados, de um Programa de Prevenção de Riscos Ambientais (PPRA), visando à preservação da saúde e integridade dos trabalhadores, por meio da antecipação, reconhecimento, avaliação e consequente controle da ocorrência de riscos ambientais existentes ou que venham a existir no meio ambiente do trabalho. 
Ademais, a citada norma considera como riscos ambientais os perigos causados à saúde do trabalhador, nascidos da exposição no meio ambiente de trabalho a agentes físicos, químicos e biológicos ${ }^{1}$.

A tendência a estabelecer uma relação entre saúde, prevenção de riscos laborais e defesa do meio ambiente também pode ser observada no âmbito da Organização Internacional do Trabalho (OIT) que, por meio do Programa Internacional para a Melhora das Condições e Meio Ambiente do Trabalho (PIACT), busca garantir a saúde e a segurança no trabalho com relação à produtividade e ao bem-estar, tanto no que se refere ao trabalho, como no que concerne ao meio ambiente vital ${ }^{2}$.

No mesmo sentido, convém mencionar a Convenção 148 da OIT sobre o meio ambiente de trabalho ${ }^{3}$, ratificada pelo Brasil em 14 de janeiro de 1982, que, no seu artigo 4.1, prevê a obrigação de adotar medidas preventivas e limitadoras dos riscos profissionais provocados pela contaminação do ar, pelos ruídos e pelas vibrações.

No âmbito do Direito Comunitário, essa tendência preventiva pode ser vislumbrada no artigo 136 da versão consolidada do Tratado da União Europeia. Este artigo estabelece que a melhora das condições de vida e de trabalho é um dos objetivos que a Comunidade e os Estados membros deverão fomentar. Para concretizar esse objetivo, a Comunidade deverá pautar suas ações e executar suas políticas buscando garantir um alto nível de proteção da saúde da humana (artigo 152). Esse imperativo comunitário foi o fundamento sobre o qual o Conselho da Comunidade Europeia adotou, em 12 de junho de 1989, a Diretiva 89/391/CEE ${ }^{4}$, relativa à aplicação de medidas para promover a melhoria da segurança e saúde dos trabalhadores, que preceitua no artigo 5.1, que o empresário tem obrigação de garantir a segurança e saúde dos trabalhadores em todos os aspectos relacionados com o trabalho.

Em matéria de meio ambiente, o artigo 174 da versão consolidada do Tratado da União Europeia prevê que um dos objetivos a alcançar através da política ambiental comunitária é a prudente e racional utilização dos recursos naturais, assim como a proteção da saúde, o que obriga a ter sempre presente o princípio de cautela e ação preventiva.

\footnotetext{
${ }^{1}$ Disponível em: www.mte.gov.br

${ }^{2}$ Disponível em: www.ilo.org

${ }^{3}$ Disponível em: www.oit.org.

${ }^{4}$ Publicada no Diário Oficial das Comunidades Europeias L 183 de 29 de junho de 1989, p. 1-8.
} 
Foi nesse cenário de vinculação entre saúde, meio ambiente do trabalho e prevenção de riscos laborais, que o Conselho da Comunidade Europeia elaborou, em 06 de fevereiro de 2003, uma Resolução que tem a finalidade de fomentar a responsabilidade social das empresas ${ }^{5}$.

Esse sistema de responsabilidade social tem como fundamento a adoção de comportamentos destinados a alcançar uma boa gestão econômica, social e ambiental, mediante a integração voluntária por parte das empresas das preocupações sociais e ambientais em suas relações comerciais e com os interlocutores sociais. É justamente na necessidade de uma boa gestão socioambiental que se encontra o elo entre defesa do meio ambiente e prevenção de riscos laborais, porque a citada Resolução considera que existe uma adequada gestão empresarial acorde com a responsabilidade social que as empresas assumem quando se faz uma análise da repercussão externa e interna da atividade empresarial.

No âmbito externo, situa-se a tutela do meio ambiente e dos consumidores por meio da qual se almeja evitar danos àquelas pessoas que não se encontram implicadas no processo produtivo, enquanto que, no âmbito da repercussão interna, encontra-se a tutela dos aspectos relativos à saúde e à segurança no trabalho, assim como a gestão dos recursos humanos. Isto porque a falta de uma gestão responsável por parte da empresa acarreta graves riscos à exploração do meio ambiente e das matérias-primas, à intervenção das empresas na política e ao respeito das normas trabalhistas.

Deste modo, a aplicação do princípio da prevenção ao meio ambiente do trabalho obriga o empregador a proteger eficazmente à saúde do trabalhador. Isso impõem, necessariamente, a adoção de um sistema de prevenção capaz de evitar os riscos laborais em todos os aspectos relacionados com o trabalho ${ }^{6}$, o que se faz através da implementação de um sistema preventivo que contemple todas as medidas elencadas na NR 9 do Ministério do Trabalho.

\subsection{A assunção do princípio da prevenção pelos órgãos de segurança e medicina do trabalho no Brasil}

\footnotetext{
${ }^{5}$ Essa Resolução foi publicada no Diário Oficial das Comunidades Europeias de 18 de fevereiro de 2003. ${ }^{6}$ Neste sentido, vide artigos. 14 e 15 da Lei de Prevenção de Riscos Laborais espanhola- Lei 31, de 8 de novembro de 1995 .
} 
De acordo com o disposto no artigo 162, da CLT, as empresas estão obrigadas a manter serviços especializados em saúde e segurança do trabalhador, instituídos proporcionalmente ao número de empregados e adequadamente à natureza dos riscos das atividades empresariais desenvolvidas.

A referida norma, ao utilizar o termo "saúde e segurança do trabalhador", deixa claro que é necessário prevenir internamente os riscos à integridade física, emocional e social no ambiente de trabalho e que decorram da atividade produtiva. Um desses órgãos é a CIPA (Comissão Interna de Prevenção de Acidentes), que possui composição paritária e é constituída por representantes dos empregados e dos empregadores. Aqueles, eleitos pelos demais empregados da empresa. Estes designados pelo empregador.

A importância da CIPA como órgão preventivo é tanta que os "cipeiros" eleitos possuem estabilidade, não podendo ser demitidos de forma arbitrária, considerando-se como tal a despedida que não se fundamentar em motivo disciplinar, técnico, econômico ou financeiro (Ato das Disposições Constitucionais Transitórias da Constituição de 1988, art.10, II). Essa garantia constitucional funciona como uma forma de blindar os "cipeiros" eleitos contra medidas persecutórias do empregador contra aquele empregado que denuncia a falta de adoção de medidas preventivas de riscos sociais no entorno laboral. As atribuições da CIPA são determinadas na NR 5, do MTE ${ }^{7}$.

\footnotetext{
${ }^{7}$ Conforme determina a NR 5, do Ministério do Trabalho e Emprego, são atribuições da CIPA: identificar os riscos do processo de trabalho, e elaborar o mapa de riscos, com a participação do maior número de trabalhadores, com assessoria do SESMT, onde houver; elaborar plano de trabalho que possibilite a ação preventiva na solução de problemas de segurança e saúde no trabalho; participar da implementação e do controle da qualidade das medidas de prevenção necessárias, bem como da avaliação das prioridades de ação nos locais de trabalho; realizar, periodicamente, verificações nos ambientes e condições de trabalho visando a identificação de situações que venham a trazer riscos para a segurança e saúde dos trabalhadores; realizar, a cada reunião, avaliação do cumprimento das metas fixadas em seu plano de trabalho e discutir as situações de risco que foram identificadas; divulgar aos trabalhadores informações relativas à segurança e saúde no trabalho; participar, com o SESMT (Serviço Especializado em Engenharia de Segurança e Medicina do Trabalho), onde houver, das discussões promovidas pelo empregador, para avaliar os impactos de alterações no ambiente e processo de trabalho relacionados à segurança e saúde dos trabalhadores; requerer ao SESMT, quando houver, ou ao empregador, a paralisação de máquina ou setor onde considere haver risco grave e iminente à segurança e saúde dos trabalhadores; colaborar no desenvolvimento e implementação do PCMSO (Programa de Controle Médico de Saúde Ocupacional) e PPRA e de outros programas relacionados à segurança e saúde no trabalho; divulgar e promover o cumprimento das Normas Regulamentadoras, bem como cláusulas de acordos e convenções coletivas de trabalho, relativas à segurança e saúde no trabalho; participar, em conjunto com o SESMT, onde houver, ou com o empregador, da análise das causas das doenças e acidentes de trabalho e propor medidas de solução dos problemas identificados; requisitar ao empregador e analisar as informações sobre questões que tenham interferido na segurança e saúde dos trabalhadores; requisitar à empresa as cópias das CAT (Comunicação de Acidente de Trabalho) emitidas; promover, anualmente, em conjunto com o SESMT, onde houver, a Semana Interna de Prevenção de Acidentes do Trabalho - SIPAT; participar, anualmente, em conjunto com a empresa, de Campanhas de Prevenção da AIDS (Disponível em www.mte.gov.br).
} 
Embora a referida norma administrativa não faça menção expressa, cabe atribuir aos membros da CIPA a prerrogativa de participar das negociações coletivas, mormente, daquelas nas quais serão negociadas normas preventivas a serem adotadas no ambiente de trabalho, para verificar se essas normas negociadas são adequadas ao sistema preventivo interno de cada empresa.

A CIPA funciona, portanto, como um importante mecanismo interno de prevenção de acidentes de trabalho e enfermidades profissionais, o que representa, em última análise, no órgão interno encarregado da aplicação do princípio da prevenção ao meio ambiente de trabalho, evitando a materialização de danos ambientais capazes de lesar a integridade física do trabalhador. A prevenção de riscos físicos, através da CIPA, e consequentemente, através de uma efetiva implantação do Programa de Promoção de Riscos Ambientais (PPRA) e do Programa de Controle Médico de Saúde Ocupacional (PCMSO) tem sido entendido pela jurisprudência do Tribunal Superior do Trabalho (TST) como um fator que deve ser levado em conta para elidir a responsabilidade empresarial nas hipóteses de danos causados por doenças ocupacionais. A existência de PCMSO e PPRA sem que, contudo, haja a adoção das medidas propostas nesses planos de forma satisfatória e efetiva induzem à culpa do empregador nos casos de doença ocupacional $^{8}$.

\subsection{Princípio da Prevenção e a antecipação do direito às atividades perigosas e insalubres}

A norma consolidada, no seu artigo 189, considera como atividades insalubres: ... as que, por sua natureza, condições ou métodos de trabalho, exponham os empregados a agentes nocivos à saúde, acima dos limites de tolerância fixados em razão da natureza e da intensidade do agente e do tempo de exposição aos seus efeitos.

Em seguida, no artigo 190, a CLT prevê que o Ministério do Trabalho e Emprego definirá os meios de proteção frente a tais atividades. Dos dispositivos legais citados, fica

\footnotetext{
8 Vid. AIRR-400-67.2007.5.04.0281, julgado pela $8^{\mathrm{a}}$ Turma do TST, sob a relatoria do Min. Dora Maria da Costa, julgado em 17112.2012, disponível em: http://aplicacao5.tst.jus.br/consultaunificada2/inteiroTeor.do?actionprintInteiroTeor\&format=html\&highli ght=true \&numeroFormatado=AIRR $\quad$ - 40067.2007.5.04.0281\&base=acordao\&rowid=AAANGhAAFAAAKJQAAS $\&$ dataPublicacao=19/10/2012\& query=ausencia adjcipa
} 
evidente a necessidade de proteger o trabalhador que labora em atividades insalubres, o que manifesta que a atuação preventiva diante de tais atividades é imperiosa.

A Súmula 289 do TST releva essa obrigação de prevenção ao estabelecer que caiba ao empregador adotar todas as medidas capazes de eliminar ou diminuir a nocividade com destaque para o uso efetivo dos equipamentos de proteção, que deverão ser devidamente aprovados pelo Ministério de Trabalho e Emprego. Com relação a esse fato, o TST entende, acolhendo as conclusões de laudo pericial, elaborado em situação de exposição a ruído, que o simples fornecimento de equipamento de proteção homologado não elide a ocorrência de insalubridade, vez que cumpre ao empregador atuar no próprio ambiente de trabalho, agindo sobre o próprio maquinário para reduzir ou até mesmo eliminar o agente insalubre ${ }^{9}$.

Nem toda exposição do trabalhador a agentes nocivos caracteriza atividade insalubre. É necessário que haja exposição a agentes nocivos em percentuais acima dos limites de tolerância previsto na NR 15, do MTE (15.1). Os graus de limite fixados na referida norma constituem padrões razoáveis de exposição que não causam danos à saúde do trabalhador e que são determinados partindo da concentração ou intensidade máxima ou mínima de exposição ao agente nocivo.

As atividades perigosas são aquelas que, por sua natureza ou métodos de trabalho, impliquem o contato permanente com inflamáveis ou explosivos em condições de risco acentuado (artigo 193, da CLT). Também se consideram como tal, nos termos da Lei $\mathrm{n}^{\circ} 7.369 / 1985$, as atividades desenvolvidas com sistema elétrico de potência em condições de risco ou com equipamentos e instalações elétricas similares, que ofereçam risco equivalente.

Têm direito a esse adicional os empregados do setor de telefonia, que trabalham em situação de perigo (Orientação Jurisprudencial 347, da SDI-I do TST), os expostos às substâncias radioativas ou radiação ionizante durante o seu labor (Orientação Jurisprudencial $\mathrm{n}^{\mathrm{o}} 345$, da SDI-I do TST), bem como aqueles que operam bomba de gasolina (Súmula 364, I, TST).

\footnotetext{
${ }^{9}$ Vid. RR-41900-31.2004.5.09.065, julgado pela $2^{\mathrm{a}}$ Turma do TST em 28.04.2010, sob a relatoria do Min. Renato de Lacerda Paiva, disponível em http://aplicacao5.tst.jus.br/consultaunificada2/inteiroTeor.do?action=printInteiroTeor\&format=html\&high light=true\&numeroFormatado=RR $\quad$ - 4190031.2004.5.09.0653\&base $=$ acordao $\&$ rowid $=$ AAANGhAA+AAAJYZAAD\&dataPublicacao $=14 / 05 / 2010 \&$ query=uso efetivo de equipamento de proteção, pesquisado em 14.11.2012.
} 
Importante destacar que o artigo 193, da CLT, faz menção à forma (natureza ou métodos de trabalho) como a atividade é desenvolvida para que haja configuração da periculosidade. Isso significa que não é o simples contato com a substância prevista na norma que faz com que a atividade seja perigosa, mas impende observar o modo como a atividade, a priori, descrita na norma, é realizada. A configuração da periculosidade pressupõe a não eliminação do perigo pela adoção de métodos de trabalho que não exponham a saúde e a integridade física do trabalhador a risco acentuado (artigo 194, da CLT).

A forma como o dispositivo celetista coloca a questão pode induzir ao equívoco de se entender que o risco acentuado é determinado partindo de níveis percentuais. Nos termos da mencionada norma regulamentadora, ao contrário, esse risco poderá existir dependendo da forma de manuseio, transporte e armazenamento da substância perigosa e não simplesmente pela exposição a certos riscos percentuais previamente determinados.

Imperioso, ainda, esclarecer que o simples fato da atividade ser perigosa ou insalubre não enseja, por si só, o pagamento dos respectivos adicionais, sendo necessário que a atividade seja tipificada na norma ${ }^{10}$.

\footnotetext{
${ }^{10}$ Nesse sentido o TST já entendeu que os comissários bordo não têm direito ao recebimento do adicional de periculosidade pelo simples fato de permanecerem no interior da aeronave durante o período de abastecimento.
}

“ADICIONAL DE PERICULOSIDADE. COMISSÁRIA DE BORDO. PERMANÊNCIA NO INTERIOR DA AERONAVE DURANTE O ABASTECIMENTO. A jurisprudência desta Corte adota o entendimento de que não é devido o pagamento do adicional de periculosidade aos trabalhadores que permanecem no interior da aeronave durante o reabastecimento, porquanto essa atividade não se insere na Norma Regulamentar $n^{\circ} 16$ do Ministério do Trabalho e Emprego. Assim, não havendo o risco acentuado a que alude o artigo 193 da CLT, não faz jus a reclamante à percepção do adicional de periculosidade. Esse posicionamento foi pacificado nesta Corte superior, mediante a edição da Súmula no 447, in verbis: 'ADICIONAL DE PERICULOSIDADE. PERMANÊNCIA A BORDO DURANTE O ABASTECIMENTO DA AERONAVE. INDEVIDO. Res. 193/2013, DEJT divulgado em 13, 16 e 17.12.2013 Os tripulantes e demais empregados em serviços auxiliares de transporte aéreo que, no momento do abastecimento da aeronave, permanecem a bordo não têm direito ao adicional de periculosidade a que aludem o art. 193 da CLT e o Anexo 2, item 1, "c", da NR 16 do MTE" . Recurso de revista conhecido e provido. CATEGORIA PROFISSIONAL ESPECIAL. AERONAUTA. ADICIONAL DE PERICULOSIDADE. COMPENSAÇÃO ORGÂNICA. PARCELA PREVISTA EM NORMA COLETIVA. SALÁRIO COMPLESSIVO. INVALIDADE. APLICAÇÃO DA SÚMULA N ${ }^{\circ} 91$ DO TST. O entendimento pacífico, no âmbito desta Corte, é de que o empregador deve discriminar as parcelas pagas separadamente. No caso, a cláusula coletiva que prevê a integração da parcela denominada compensação orgânica no cômputo da remuneração fixa é nula, pois está caracterizado o pagamento de salário compressivo, forma de contraprestação não admitida pelo ordenamento jurídico trabalhista e pela jurisprudência pacificada nesta Corte superior, nos termos da Súmula $n^{\circ}$ 91. Recurso de revista não conhecido. HORAS EXTRAS. RECURSO DESFUNDAMENTADO. O recurso de revista não merece conhecimento, porquanto a parte não indica violação de lei e/ou da Constituição Federal, tampouco colaciona arestos para confronto de teses, nos termos das alíneas "a" e "c" e do inciso II do $§ 1^{\text {o }}$-A do artigo 896 da CLT, pelo que o apelo, no aspecto, revela-se desfundamentado. Recurso de revista não conhecido. ( RR - 1700043.2006.5.02.0318, Relator Ministro: José Roberto Freire Pimenta, Data de Julgamento: 24/06/2015, 
Neste particular cabe fazer uma crítica ao critério da tipificação legal como requisito necessário à caracterização da insalubridade e periculosidade, já que esse método, se entendido como fator determinante, não atende ao princípio de prevenção que deve nortear o meio ambiente do trabalho, nem tampouco ao princípio da proteção e à tendência de promoção de uma ética ambiental e de uma sustentabilidade holística.

O caráter fundamental do princípio da prevenção, como reitor do arcabouço valorativo do Direito Ambiental e, na atual conjuntura de construção de uma ética ambiental, também do Direito do Trabalho, impõe uma diminuição da importância desse critério para determinação da insalubridade ou periculosidade. Destarte, se uma atividade, mesmo não estando prevista na norma regulamentadora do MTE, for considerada, por demonstração pericial, como insalubre ou perigosa, mister se faz que o empregador adote todas as medidas preventivas para eliminar o risco e, se tal eliminação não acontecer, que haja o pagamento do adicional respectivo.

Afastar a tipificação do agente insalubre ou perigoso como critério determinante para a existência desses fatores em uma determinada atividade torna-se ainda mais premente quando se trata de atividades potencialmente causadoras de significativa degradação do meio ambiente, visto que, nesses casos, tais agentes já se encontram tipificados no Estudo Prévio de Impacto Ambiental (EPIA), de cuja elaboração a entidade sindical deveria, obrigatoriamente, participar, mormente, no ponto que atine identificação dos fatores de risco para os trabalhadores.

A prescrição legal, dos artigos 189 e 190 da CLT, visa a incumbir o MTE de aprovar o quadro das atividades e operações insalubres e estabelecer os critérios de caracterização desses agentes. Quando se analisa esses artigos, vê-se que a finalidade desses preceitos é criar um modelo de proteção que respeite a saúde humana. Por outra parte, fazendo-se uma interpretação dos mencionados artigos à luz do princípio da prevenção, chega-se à conclusão de que, se valer da omissão legal para não fixar os adicionais mencionados em casos em que as condições de trabalho e a exposição a agentes nocivos causam danos à saúde, é colocar de lado a necessidade de prevenção que a defesa do meio ambiente, no qual está incluído o meio ambiente laboral, requer como forma de garantir a sustentabilidade, prevista no caput do artigo 225, da CF/1988.

$2^{\mathrm{a}}$ Turma, Data de Publicação: DEJT 01/07/2015, pesquisado em www.tst.jus.br, em 20.07.2015, às $9: 30 \mathrm{~h})$. 
Convém, ainda, esclarecer que é possível admitir que o enquadramento legal de certa atividade perigosa ou insalubre se dê a partir de normas coletivas (acordos e convenções coletivas). $\mathrm{O}$ artigo $7^{\circ}$, da Constituição brasileira, reconhece direitos mínimos ao trabalhador, que, pela sua natureza de indispensáveis a um padrão mínimo de proteção, se tornam irrenunciáveis. Contudo, nada impede que tais direitos sejam ampliados pelos acordos e convenções coletivas de trabalho, cabendo aos sindicatos, portanto, o dever institucional de fomentar estudos técnicos capazes de avaliar os riscos para a saúde do trabalhador que podem decorrer da sua exposição a certos agentes nocivos que não encontram amparo na classificação legal do MTE.

O que fica terminantemente proibido e excluído do âmbito de negociação sindical é a possibilidade de redução dos percentuais e índice fixados, porque estes funcionam como um padrão mínimo de proteção legal, que não poderá ser afastado pela vontade das partes, nem mesmo a coletiva, tornando-se, portanto, inderrogáveis. Incumbir os sindicatos do papel de incluir nas suas normas coletivas agentes insalubres e perigosos que são próprios da atividade desenvolvida pela categoria que representa figura, ainda, como um meio de efetivar o princípio da participação e da cooperação em matéria de tutela do meio ambiente, já que as entidades sindicais são atores sociais aos quais cabe institucionalmente a defesa dos interesses coletivos, dentro do qual se insere, claramente, o meio ambiente de trabalho.

Indubitavelmente, o princípio da prevenção, quando aplicado como fator norteador do Direito do Trabalho, opera o necessário e importante papel de ressignificar os institutos do adicional de insalubridade e periculosidade, como forma de criar uma política preventiva dentro das empresas, com vistas a garantir que se alcance um desenvolvimento sustentável holístico cujo ponto de partida é a ética ambiental.

\subsection{O Princípio da Prevenção e a Responsabilidade Objetiva do empregador em matéria de danos ao trabalhador}

No direito do trabalho, a responsabilidade civil do empregador se encontra regulada no artigo $7^{\circ}$, XXVII, da Constituição de 1988, enfocando o pressuposto da culpa nos casos de acidente de trabalho. O problema surge quando se analisa a questão que envolve tais acidentes sob a perspectiva do meio ambiente de trabalho, porque o artigo 14, parágrafo $1^{\circ}$, da Lei $\mathrm{n}^{\mathrm{o}} 6.938 / 81$, prescreve que a responsabilidade por danos ambientais é objetiva. Destarte, entender que a responsabilidade do empregador nos casos 
de danos decorrentes de acidente deve também ser objetiva, vez que tais danos ocorrem no ambiente de trabalho, a priori, afrontaria o disposto na Carta Magna.

Entretanto, tal violação não acontece, porque, nessas hipóteses, se deve ter uma interpretação conjunta da norma constitucional citada em comento com outros dispositivos constitucionais.

O primeiro deles é o artigo $1^{\circ}$, III, da $\mathrm{CF} / 1988$, que reconhece como princípio fundamental da ordem jurídica brasileira, a dignidade da pessoa humana, que no dizer de Radbruch (1997), consiste no valor que impõe a necessidade de respeito ao indivíduo pela sua simples condição de integrante do gênero humano.

Assim sendo, a adoção da teoria da responsabilidade objetiva nos casos de dano à pessoa trabalhadora no ambiente laboral funciona como pressuposto para o respeito do referido princípio constitucional, a fim de que a reparação efetiva das lesões sofridas pelo trabalhador não esbarrem no elemento intencional da conduta do empresário, principalmente, quando se observa que ele, no momento em que empreende uma atividade econômica, assume os riscos que dela dimanam, o que não justifica que o trabalhador seja privado do respeito aos seus direitos fundamentais quando ingressa na empresa.

Além disso, deve-se ter em conta o artigo 170, caput, e inciso VII, da Carta Magna. O caput do referido texto constitucional reconhece que a valorização do trabalho humano e a livre iniciativa são os fundamentos da ordem econômica, que tem como uma de suas finalidades alcançarem a justiça social. O problema surge no momento de equacionar esses dois axiomas tão antagônicos, quais sejam, valorização do trabalho humano e livre iniciativa.

De acordo com o inciso VI e VIII, do artigo analisado, a compatibilização desses dois valores requerem, obrigatoriamente, a defesa do meio ambiente e a busca pelo pleno emprego, de modo que se pode considerar como pleno o emprego no qual o meio ambiente de trabalho é encarado como um pressuposto necessário para se alcançar uma sustentabilidade holística, na qual, ademais do respeito aos recursos naturais durante o processo produtivo, deve-se também primar pelo respeito ao indivíduo que trabalha naquela ambiente e a sua saúde, como pressupostos para se alcançar inclusão social.

Um emprego pleno é aquele em que o trabalhador tem os seus direitos e garantias fundamentais respeitados e estes funcionam como um limite para a livre iniciativa e como um critério determinante da defesa do meio ambiente. 
Por fim, o princípio da prevenção ganha relevo na determinação da responsabilidade objetiva do empregador em hipóteses de danos ao trabalhador e se compatibiliza com o contido no artigo $7^{\circ}$, caput, da atual Constituição, na medida em que esse dispositivo legal reconhece que, no decorrer dos seus incisos, se encontram previstos direitos mínimos para garantir um padrão de dignidade ao trabalhador que não pode ser afastado. Da dicção da norma constitucional mencionada, resta claro a possibilidade de ampliação dos direitos arrolados, o que faz com a previsão normativa ganhe um caráter de norma de direito mínimo necessário.

Aliado a isto, impende observar que o conteúdo do princípio da prevenção se destina a evitar a produção do dano, o que requer não apenas um padrão curativo, que se teria ao responsabilizar o patrão apenas nos casos em que ele atuou com culpa, senão impõe também a adoção de um modelo propriamente preventivo, o que, em termos de acidente de trabalho, somente pode ser atingido com a adoção da teoria da responsabilidade objetiva, mormente, nos casos em que a atividade desenvolvida pelo empresário é potencialmente causadora de significativa degradação do meio ambiente.

Em última análise, a objetivação da responsabilidade do empregador encontra arrimo em todos os axiomas constitucionais esboçados e figura como um instrumento que visa a permitir o desenvolvimento humano, na medida em que o trabalho constitui uma das principais fontes de dignificação do ser humano, bem como um fruto expressivo da ética ambiental e da sustentabilidade holística.

\section{Considerações finais}

A defesa do meio ambiente não pode ser feita, levando em conta apenas uma concepção restrita desse bem jurídico. Para a sua integral tutela é preciso encará-lo como uma peça necessária para promover o desenvolvimento social e humano.

A interação e interdependência do homem com o seu entorno, quando visualizada sob a perspectiva dos direitos fundamentais, impõe um novo modelo de respeito, cuidado e responsabilidade, no qual o ser humano não figura como o dono do meio em que vive, mas como responsável por ele, devendo protegê-lo para as presentes e futuras gerações, partindo de valores éticos e jurídicos que impõem reciprocidade e alteridade.

Tais valores condicionam a formulação de um novo conceito de ética, a ambiental cujo fundamento é a sustentabilidade social, imprescindível vetor de 
desenvolvimento humano. Nessa perspectiva, a ética ambiental e a sustentabilidade, pautadas sobre axiomas de reciprocidade e alteridade, cumprem a finalidade de atuar como vetores de uma ressignificação do Direito do Trabalho, a partir da aplicação do princípio da prevenção a esse ramo do direito.

No presente artigo, pretendeu-se demonstrar que o princípio mencionado dá um novo conteúdo a figuras jurídicas tradicionais previstas na legislação trabalhista. Em primeiro lugar, atribuindo novas competências preventivas à CIPA; em segundo, rompendo com o clássico entendimento de que a caracterização de uma atividade como insalubre ou perigosa depende, necessariamente, de uma prévia tipificação da normativa administrativa; e, em terceiro, impondo um padrão de responsabilidade objetiva nos casos de danos causados ao trabalhador no seu entorno laboral.

A aplicação do princípio da prevenção ao Direito do Trabalho como forma de garantir que esse ramo do Direito se torne mais humano e menos monetário viabiliza o cumprimento de uma finalidade constitucional, que consiste em harmonizar três princípios da ordem econômica, quais sejam: a valorização do trabalho, a livre iniciativa e o pleno desenvolvimento da pessoa humana. É possível alcançar essa harmonização através da garantia do trabalho sustentável por meio da defesa do meio ambiente, sobretudo, o laboral, como pressuposto do processo produtivo que respeite o indivíduo e meio ambiente no qual ele trabalha.

\section{Referências bibliográficas}

BOFF, Leonardo. Ética e Sustentabilidade. Caderno de Debate Agenda 21. Brasília: Ministério de Meio Ambiente, 2006.

BRANCO, Murgel. Conflitos conceituais nos estudos sobre meio ambiente. Estudos Avançados, v. 9, n. 23, p. 217, São Paulo, 1995.

\section{BRASIL. CONSTITUIÇÃO DA REPÚBLICA FEDERATIVA DO BRASIL} Brasília, 05 de outubro de 1988. Ambiente.

Lei n⿳ 6.938, de 31 de agosto de 1981. Dispõe sobre a Política Nacional do Meio

Decreto-lei 5.452, de $1^{\circ}$ de maio de 1943. Aprova a Consolidação das Leis do Trabalho.

Ministério do Trabalho e emprego. NR 9 - programa de prevenção de riscos $\overline{\text { ambientais. Texto dado pela Portaria SSST n. }}{ }^{\text {2 } 25,} 29$ de dezembro de 1994. 
OIT. Convenção no 148 sobre a Proteção dos Trabalhadores Contra os Riscos Profissionais Devidos à Contaminação do Ar, ao Ruído e às Vibrações no Local de Trabalho.

RADBRUCH, Gustav. Filosofia do direito. [tradução e prefácio prof. L. Cabral de Moncada] 6a ed. Coimbra: Arménio Amado - Editor, sucessor, 1997.

SILVA, José Afonso da. Curso de Direito Ambiental Constitucional. 3. ed. rev. atual. São Paulo: Malheiros, 2000.

UE. Tratado Da União Europeia E Do Tratado Que Institui A Comunidade Europeia. Jornal Oficial da União Europeia, 29.12.2006

WOLKMER, Maria de Fátima Schumcher; PAULITSCH, Nicole da Silva. Ética ambiental e crise ecológica: reflexões necessárias em busca da sustentabilidade. Veredas do Direito, v. 8, n. 16, p. 211-233, Belo Horizonte, Julho-Dezembro/2011.

TST. AIRR-400-67.2007.5.04.0281, julgado pela 8a Turma em 17.12.2012

TST. RR-41900-31.2004.5.09.065, julgado pela 2a Turma em 28.04.2010

TST. Súmula 364, I. Adicional de periculosidade. Exposição eventual, permanente e intermitente - Resolução 174/2011, DEJT divulgado em 27, 30 e 31.05.2011. 